Louisiana State University

LSU Digital Commons

5-26-2016

\title{
CO Adsorption on Au Nanoparticles Grown on Hexagonal Boron Nitride/Rh(111)
}

W. C. McKee

M. C. Patterson

Louisiana State University

D. Huang

Texas A\&M University

J. R. Frick

Louisiana State University

R. L. Kurtz

Louisiana State University

See next page for additional authors

Follow this and additional works at: https://digitalcommons.Isu.edu/physics_astronomy_pubs

\section{Recommended Citation}

McKee, W., Patterson, M., Huang, D., Frick, J., Kurtz, R., Sprunger, P., Liu, L., \& Xu, Y. (2016). CO Adsorption on Au Nanoparticles Grown on Hexagonal Boron Nitride/Rh(111). Journal of Physical Chemistry C, 120 (20), 10909-10918. https://doi.org/10.1021/acs.jpcc.6b01645

This Article is brought to you for free and open access by the Department of Physics \& Astronomy at LSU Digital Commons. It has been accepted for inclusion in Faculty Publications by an authorized administrator of LSU Digital Commons. For more information, please contact ir@lsu.edu. 
Authors

W. C. McKee, M. C. Patterson, D. Huang, J. R. Frick, R. L. Kurtz, P. T. Sprunger, L. Liu, and Y. Xu 


\title{
CO Adsorption on Au Nanoparticles Grown on Hexagonal Boron Nitride/Rh(111)
}

\author{
W. C. McKee, ${ }^{\dagger}$ M. C. Patterson, ${ }^{\ddagger}$ D. Huang, ${ }^{\S}$ J. R. Frick, ${ }^{\ddagger}$ R. L. Kurtz, ${ }^{\ddagger}$ P. T. Sprunger, ${ }^{\ddagger}$ L. Liu, ${ }^{*}{ }^{\S}$ \\ and $\mathrm{Y} . \mathrm{Xu}^{*, \dagger}$
}

${ }^{\dagger}$ Department of Chemical Engineering and ${ }^{\ddagger}$ Department of Physics and Astronomy and CAMD, Louisiana State University, Baton Rouge, Louisiana 70803, United States

${ }^{\S}$ Department of Materials Science and Engineering, Texas A\&M University, College Station, Texas 77843, United States

\section{Supporting Information}

ABSTRACT: $\mathrm{CO}$ adsorption on size-controlled $\mathrm{Au}$ nanoparticles grown on an $h-\mathrm{BN} / \mathrm{Rh}(111)$ nanomesh surface has been examined to probe their potential catalytic properties. A combination of high-resolution electron energy loss spectroscopy (HREELS), temperature-programmed desorption (TPD), and density functional theory (DFT) calculations demonstrate that the $\mathrm{CO}$ adsorption strength depends heavily on the $\mathrm{Au}$ deposition coverage and particle morphology. Particles resulting from low Au coverages deposited at the liquid nitrogen temperature exhibit significantly enhanced $\mathrm{CO}$ binding relative to bulk crystalline Au. The resulting CO TPD

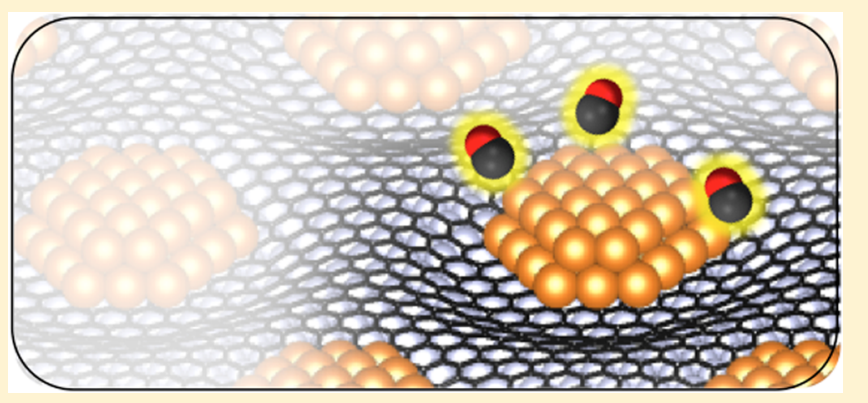
spectra, and the significantly red-shifted $\mathrm{C}-\mathrm{O}$ stretching frequency and negative charging of the Au nanoparticles as evidenced by HREELS and DFT, all correspond to those reported for catalytically active Au nanoparticles grown on reactive metal oxides, even though the $h$ - $\mathrm{BN} / \mathrm{Rh}(111)$ surface is free of carbon, oxygen, or defects. DFT modeling further suggests that the enhanced CO adsorption occurs at highly undercoordinated $\mathrm{Au}$ atoms on the perimeters of the nanoparticles. As the Au coverage is increased, the $\mathrm{CO}$ adsorption energy and $\mathrm{C}-\mathrm{O}$ stretching frequency converge toward values associated with bulk Au. Annealing to $600 \mathrm{~K}$ results in bulk-like $\mathrm{CO}$ adsorption characteristics at any $\mathrm{Au}$ coverage. These results suggest that the $h$ - $\mathrm{BN} / \mathrm{Rh}(111)$ surface represents a potential platform for evaluating the role of $\mathrm{Au}$ vs support in low-temperature $\mathrm{CO}$ oxidation.

\section{INTRODUCTION}

The remarkable activity of Au nanoparticles (NPs) toward lowtemperature $\mathrm{CO}$ oxidation has been known for over three decades now, ${ }^{1}$ but parsing the various effects responsible for their catalytic properties remains challenging. Size is apparently critical: Au NPs which are monolayer and bilayer in height and $2-3 \mathrm{~nm}$ in diameter exhibit the highest catalytic activity, while those $>5 \mathrm{~nm}$ are essentially inert. ${ }^{2-6}$ Similarly, negative charging of $\mathrm{Au}$ NPs by electron transfer from transition metal (TM) oxide supports is widely thought to be responsible for their catalytic activity for $\mathrm{CO}$ oxidation. ${ }^{4,5,7-11}$ The role of the support in catalyzing $\mathrm{CO}$ oxidation is not yet completely understood. Though the morphologies of Au NPs undoubtedly result from their interactions with the support, whether TM oxides are directly involved in $\mathrm{CO}$ oxidation by assisting in the activation of one of the reactants or by functioning as an oxygen or $\mathrm{CO}$ reservoir, or not at all, is still an active topic of catalysis research. ${ }^{12-16}$

It is therefore of fundamental interest to probe the properties of $\mathrm{Au}$ NPs that exhibit similar size, morphology, and charge distribution to those supported on TM oxides that have been found to be catalytically active but exist on an inert and defectfree surface. Recently the preparation of dense arrays of sizecontrolled, well-ordered NPs by deposition onto patterned substrates has received increased attention. ${ }^{17}$ Monolayer graphene and hexagonal boron nitride $(h-\mathrm{BN})$ films grown epitaxially on TM surfaces show unique promise in this regard. ${ }^{18-23}$ The lattice mismatch between graphene or $h$-BN and TM surfaces yields an undulating corrugated superstructure, which provides large arrays of identical, regularly spaced trapping sites for cluster nucleation. Both 2D films are easily prepared, contain no oxygen, and are chemically inert to well above room temperature. In particular, $\mathrm{BN} / \mathrm{Rh}(111)$ has been demonstrated to be stable following exposure to ambient air, water, and perchloric acid. ${ }^{24,25}$ Graphene moiré-supported TM clusters are already being explored for potentially unique catalytic properties. ${ }^{26,27}$

We have recently demonstrated that $\mathrm{Au}$ NPs of size and height that are thought to be active for low-temperature $\mathrm{CO}$ oxidation can be prepared via deposition onto $h$-BN/ $\mathrm{Rh}(111){ }^{28}$ The $h$-BN/Rh(111) nanomesh consists of highlying "wire" regions as well as low-lying "pore" regions that are essentially flat, ${ }^{25,29-31}$ the latter of which can trap Au clusters and limit their diameters to $<3 \mathrm{~nm}$ for up to $5 \mathrm{ML}$ equivalent of

Received: February 17, 2016

Revised: April 11, 2016 
$\mathrm{Au}$ coverage. With $5 \mathrm{ML}$ of $\mathrm{Au}$ deposited at $115 \mathrm{~K}$ and annealed to room temperature, the resulting NPs are densely packed $\left(\sim 0.08\right.$ clusters $\left./ \mathrm{nm}^{2}\right)$, the density of which rivals $\mathrm{Au}$ NP samples obtained on alumina and iron oxide thin films, ${ }^{32}$ and exhibit long-range monodispersity on micron scales (Figure 1). ${ }^{28}$ STM measurements indicate primarily an "upward" as

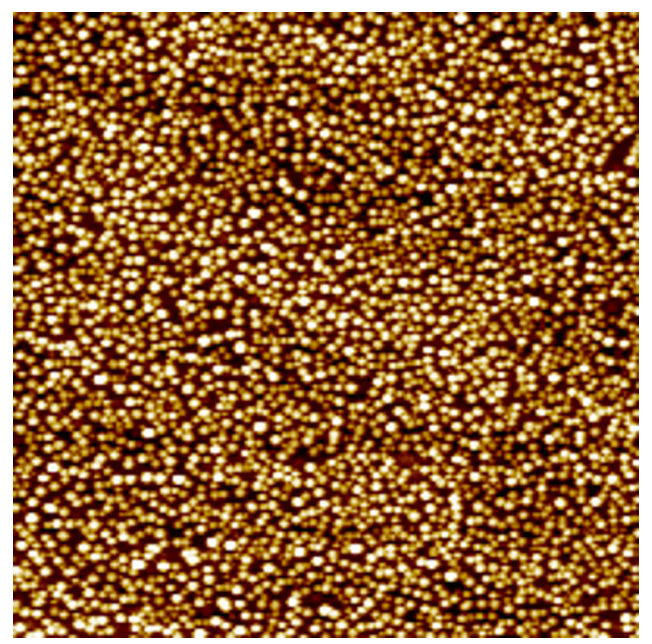

Figure 1. $2000 \times 2000 \AA^{2}$ scanning tunneling microscopy (STM) image of $5 \mathrm{ML}$ of $\mathrm{Au}$ deposited on $h-\mathrm{BN} / \mathrm{Rh}(111)$ at $115 \mathrm{~K}$ and imaged at $300 \mathrm{~K}$. Reproduced with permission from ref 28. Copyright 2014 American Physical Society.

opposed to "outward" growth mode, as the resulting particles exhibited diameters clustered around $2.9 \mathrm{~nm}$ and heights of 10-25 $\AA^{28}$ The height of the NPs can be limited by the deposition temperature. For example, $0.16 \mathrm{ML}$ of Au deposited at $115 \mathrm{~K}$ yields $\mathrm{Au}$ NPs that are primarily one layer high and occupy $\sim 80 \%$ of the pores. Conversely, at the same $\mathrm{Au}$ coverage, NPs formed at room temperature fill $\sim 40 \%$ of the pores and exhibit a nearly equal number of mono- and bilayer clusters but are still confined to the pore regions. This difference is presumably due to a high diffusion barrier for an $\mathrm{Au}$ adatom on this surface. ${ }^{33}$ In comparison, Au deposited on graphene $/ \mathrm{Ru}(0001)$ forms exclusively large flat bilayers that span multiple moiré cells ${ }^{20,21,34}$ because of low diffusion barriers for Au adatoms ${ }^{35}$ and for small Au clusters. ${ }^{36}$ Annealing of $\mathrm{Au}$ on $\mathrm{h}-\mathrm{BN} / \mathrm{Rh}(111)$ up $500{ }^{\circ} \mathrm{C}$ would eventually cause $\mathrm{Au}$ to alloy into the $\mathrm{Rh}$ surface. ${ }^{37}$

Despite their promising size and diameter, whether Au NPs on $h$-BN/Rh(111) exhibit other properties associated with catalytically active Au supported on TM oxides has yet to be established. Herein we use $\mathrm{CO}$ as a probe molecule to further examine the properties of Au NPs grown on $h$-BN/Rh(111), by means of high resolution electron energy loss spectroscopy (HREELS), temperature-programmed desorption (TPD), and density functional theory (DFT) calculations. Notably, significantly enhanced $\mathrm{CO}$ binding and red-shifted $\mathrm{C}-\mathrm{O}$ frequency compared to bulk $\mathrm{Au}$ surfaces are observed for $\mathrm{Au}$ $\mathrm{NPs}$ grown on $h-\mathrm{BN} / \mathrm{Rh}(111)$ under certain conditions, indicating that highly undercoordinated sites and negative charging are the features key to the reactivity of Au NPs, at least as far as $\mathrm{CO}$ adsorption is concerned. Since these features are also exhibited by Au NPs supported on TM oxides, ${ }^{11,38}$ these results suggest that $\mathrm{Au}$ NPs supported on $h-\mathrm{BN} / \mathrm{Rh}(111)$ are potential model catalysts for low-temperature $\mathrm{CO}$ oxidation and possibly other reactions requiring activation by electron transfer (such as $\mathrm{CO}_{2}$ reduction $^{39}$ ) and furthermore that $h$-BN/ $\mathrm{Rh}$ (111) may be an ideal platform for evaluating the roles of metal vs support in reactions catalyzed by metal NPs in general, by offering an oxygen-free surface that can nonetheless stabilize NPs at appropriate temperature. Moreover, the carbon-free nature of the $h$-BN film may avoid further complicating the spectroscopic characterization of carbon species in potential organic reactants on nanoparticles formed on the pore-wire structure as opposed to nanoparticles formed on graphene.

\section{METHODS}

TPD and HREELS experiments were performed in two different ultrahigh vacuum (UHV) surface science chambers, where the same recipes were followed for the $h-\mathrm{BN} / \mathrm{Rh}(111)$ surface preparation and $\mathrm{Au}$ deposition to ensure the consistency between the two sets of experimental measurements.

2.1. Sample Preparation. An $\mathrm{Rh}(111)$ single crystal was cleaned by repeated cycles of $\mathrm{Ne}^{+}$or $\mathrm{Ar}^{+}$sputtering and flashing by an e-beam heater to $1200 \mathrm{~K}$. Upon obtaining a clean $\mathrm{Rh}(111)$ surface, a monolayer $h$-BN nanomesh was synthesized by exposure to 80-120 langmuirs of borazine vapor (gas exposures are herein given in langmuirs; 1 langmuir $=1 \times 10^{-6}$ Torr $\cdot \mathrm{s}$ ) with the sample held at $1000 \mathrm{~K}$. This procedure routinely results in a well-ordered, extended-size $h$-BN monolayer as monitored by low-energy electron diffraction (LEED), Auger electron spectroscopy (AES), EELS, and STM, with no elemental impurities present within the sensitivity of Auger. $^{25,28,29}$ Prior to Au dosing, full coverage of the $\mathrm{Rh}(111)$ surface by the $h$-BN film was verified via EELS and TPD measurements by dosing $\mathrm{CO}$ on the bare nanomesh. The lack of an EELS peak $\sim 248 \mathrm{meV}$, corresponding to $\mathrm{CO}$ adsorbed on $\mathrm{Rh}^{40}$ and the lack of any CO TPD feature at $470-490 \mathrm{~K}$, corresponding to $\mathrm{CO}$ desorption from $\mathrm{Rh}^{41}$ confirmed complete coverage of $\mathrm{Rh}(111)$ by $h-\mathrm{BN}$. Au was then deposited on the $h$-BN covered $\mathrm{Rh}(111)$ substrate from home-built thermal evaporators. Au coverage was calibrated via the Auger break point method by evaporating $\mathrm{Au}$ on the clean $\mathrm{Rh}(111)$ substrate, and each sample was checked for cleanliness by ensuring that Auger spectra showed no adventitious carbon or other species. All deposition amounts here are defined as ML equivalents, where $1 \mathrm{ML}$ corresponds to the number density of $\mathrm{Rh}$ atoms in the $\mathrm{Rh}(111)$ surface.

2.2. TPD. TPD experiments were carried out in an UHV chamber with a base pressure of $5.0 \times 10^{-10}$ Torr. The chamber is equipped with a quadrupole mass spectrometer (QMS) (UTI 100C Precision mass analyzer), AES (PerkinElmer 15-155 cylindrical mirror analyzer), LEED (PRI 11-020), and a sputter ion gun (PerkinElmer 04-161 $2 \mathrm{kV}$ ). The sample temperature was measured by a C-type thermocouple spot-welded to the back of the $\mathrm{Rh}(111)$ sample. High purity $\mathrm{CO}$ was dosed on the $\mathrm{Au}$ clusters supported on $h$-BN/Rh(111) at liquid nitrogen temperature $(77 \mathrm{~K})$, designated herein as $\mathrm{LN}_{2}$, through a leak valve. 30 langmuir $\mathrm{CO}$ exposure was employed to ensure saturation coverage on the Au clusters. Following $\mathrm{CO}$ exposure, the sample was accurately positioned in front of the aperture of the shield that surrounds the QMS, ${ }^{42}$ and the thermal desorption products were monitored while the temperature was ramped at a rate of $3.0 \mathrm{~K} / \mathrm{s}$.

2.3. HREELS. HREELS experiments were performed in a UHV chamber with a base pressure of $1.0 \times 10^{-10}$ Torr consisting of two chambers connected by a gate valve. The preparation chamber contains a sputter gun, leak valves to dose 

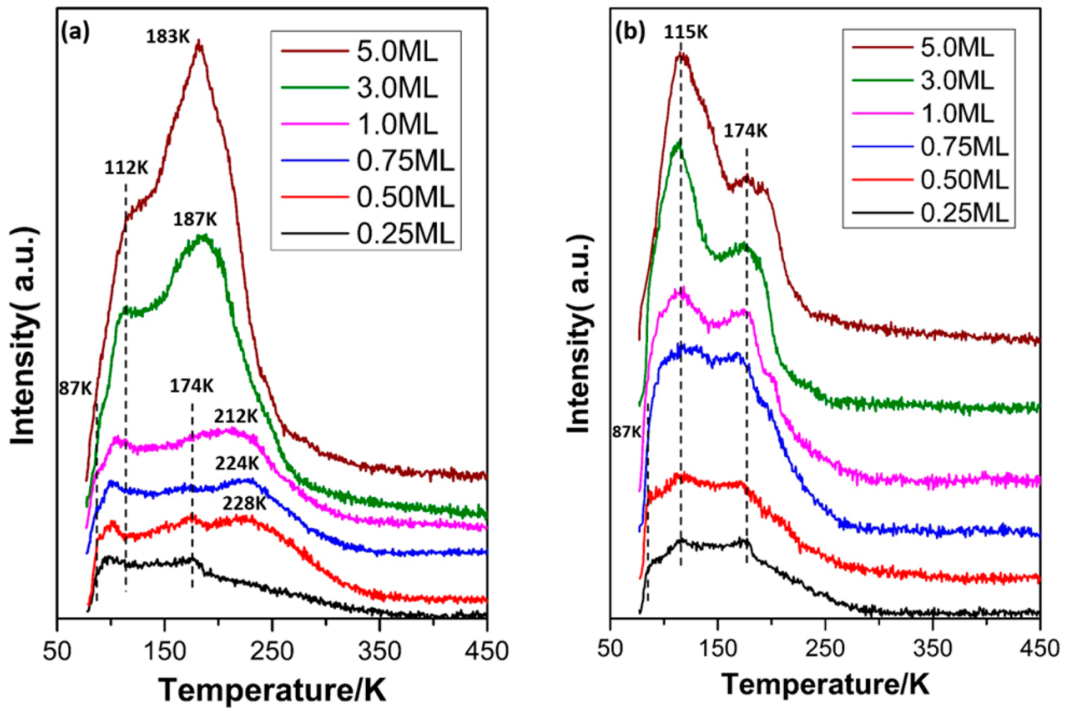

Figure 2. $\mathrm{CO} \mathrm{TPD}$ on $\mathrm{Au} / \mathrm{h}-\mathrm{BN} / \mathrm{Rh}(111)$ for various $\mathrm{Au}$ depositions at saturation $\mathrm{CO}$ coverage. (a) Au deposited at $\mathrm{LN}_{2}$. (b) $\mathrm{Au}$ deposited at room temperature and then annealed to $600 \mathrm{~K}$.

various gases, LEED, and a single-pass cylindrical mirror analyzer with coaxial electron gun for Auger electron spectroscopy. The EELS chamber contained an LK Technologies LK2000 electron energy loss spectrometer. All vibrational EELS measurements were taken with a primary beam energy of $7 \mathrm{eV}$ in the specular geometry (with respect to the surface normal, incident beam angle $=$ exiting beam angle $=$ $60^{\circ}$ ) with energy resolution of order $8-10 \mathrm{meV}$ measured by the fwhm of the elastically scattered beam. The sample manipulator was cooled to $90 \mathrm{~K}$ using a liquid nitrogen flow cryostat, with sample temperatures measured by a type $\mathrm{K}$ thermocouple in contact with the sample stage. Measurements of adsorbed $\mathrm{CO}$ were done by first preparing the $h-\mathrm{BN}$ nanomesh and evaporating $\mathrm{Au}$ on the sample preparation manipulator and then transferring the sample into the EELS system, cooling the manipulator to $90 \mathrm{~K}$, and holding the sample at $\mathrm{LN}_{2}$ throughout gas dosing and EELS measurements. Unless otherwise noted, EELS spectra reported below were normalized to the height of the elastic peak, with offsets added for clarity.

2.4. DFT Calculations. Periodic density functional theory (DFT) calculations were performed using the Vienna $A b$ Initio Simulations Package (VASP) ${ }^{43}$ in the generalized gradient approximation (GGA) of Perdew, Burke, and Ernzerhof ${ }^{44}$ and using the vdW-corrected Bayesian error estimation functional (BEEF) of Wellendorff et al. ${ }^{45}$ As will be shown below, BEEF yields a better description of $\Delta E_{\mathrm{CO}}$ on $\mathrm{Au}$ than $\mathrm{PBE}$ when compared to experimental measurements, although the calculated lattice constants are slightly worse. The core electrons were described by the projector augmented wave method $^{46}$ and the Kohn-Sham valence electrons (including $\mathrm{Rh}(4 \mathrm{~d} 5 \mathrm{~s}), 229 \mathrm{eV}$ cutoff; $\mathrm{Au}(5 \mathrm{~d} 6 \mathrm{~s}), 230 \mathrm{eV}$ cutoff; $\mathrm{B}(2 \mathrm{~s} 2 \mathrm{p})$, 319 eV cutoff; C(2s2p), $400 \mathrm{eV}$ cutoff; $\mathrm{N}(2 \mathrm{~s} 2 \mathrm{p}), 400 \mathrm{eV}$ cutoff; and $\mathrm{O}(2 \mathrm{~s} 2 \mathrm{p}), 400 \mathrm{eV}$ cutoff) were expanded in a plane wave basis set up to a cutoff energy of $400 \mathrm{eV}$. The electronic states were smeared using a first-order Methfessel-Paxton scheme ${ }^{47}$ with a width of $0.1 \mathrm{eV}$. All total energies were extrapolated back to $0 \mathrm{~K}$.

The $h$-BN pore-wire structure on $\mathrm{Rh}(111)$ was modeled as a $(13 \times 13)-h-B N$ monolayer on $(12 \times 12)-\mathrm{Rh}(111)$ surface unit cell ("13-on-12", see Figure S1 in Supporting Information), consisting of a total of $169 \mathrm{~B}, 169 \mathrm{~N}$, and $432 \mathrm{Rh}$ atoms. The calculated lattice constant for Rh is $3.824 \AA$ (PBE) and $3.848 \AA$ (BEEF), in close agreement with experiment $(3.80 \AA) .{ }^{48}$ The $\mathrm{Rh}(111)$ surface was modeled as a semi-infinite three metal layer slab. Prior to geometry optimization, an initially flat $h$-BN monolayer was placed on one side of the $\mathrm{Rh}$ slab and fully relaxed. The entire $h$-BN monolayer, the top layer of $\mathrm{Rh}$ atoms, and any $\mathrm{Au}$ and $\mathrm{CO}$ adsorbed thereon were fully relaxed while the bottom two layers of Rh were fixed at their bulk positions. Approximately $16 \AA$ of vacuum space (measured from the top of the $h$-BN film) and electrostatic decoupling ${ }^{49}$ were applied in the $z$ direction to accommodate the presence of the Au cluster and any adsorbed $\mathrm{CO}$ and minimize electronic interactions between neighboring slab images. Because of the large size of the surface unit cell, the surface Brillouin zone was sampled at the $\Gamma$ point only. Further structural details of the optimized $h$ $\mathrm{BN} / \mathrm{Rh}(111)$ nanomesh model have been reported previously. ${ }^{28,50}$

$\mathrm{CO}$ adsorption on bulk $\mathrm{Au}$ crystalline surfaces was also considered for comparison. The calculated Au lattice constant is $4.157 \AA$ ( $\mathrm{PBE})$ and $4.208 \AA$ (BEEF) compared to the experimental value of $4.08 \AA^{48} \mathrm{An} \mathrm{Au}(111)$ surface was modeled by a four-layer slab with a $(3 \times 3)$ surface unit cell. The $\mathrm{Au}(211)$ surface was modeled by a three-layer (in the direction normal to the terrace) slab with the terrace being four atoms wide and three atomic rows deep. Finally, the $\mathrm{Au}(563)$ surface was modeled by a three-layer (again in the direction normal to the terrace) slab with the terrace being three atoms wide and four atomic rows deep. The choice of the $\mathrm{Au}$ structures is explained later. Electrostatic decoupling and at least $12 \AA$ of vacuum space were applied in the $z$ direction to minimize interactions of neighboring slab images. During geometry optimization the top two layers of the $\mathrm{Au}(111)$ slab and the top layers of the $\mathrm{Au}(211)$ and (563) slabs (which includes also the row of atoms directly beneath the step edge) along with any adsorbed $\mathrm{CO}$ were fully relaxed, while the bottom layers of the Au slabs were held fixed at their bulk positions. The Brillouin zone was sampled using a $5 \times 5 \times 1$ Monkhorst-Pack k-point grid for all three surfaces. The convergence criterion for all geometry optimizations in this study was set to $0.05 \mathrm{eV} / \AA$ for each relaxed degree of freedom. 
The adsorption energy $(\Delta E)$ of a $\mathrm{CO}$ molecule was calculated as $\Delta E_{\mathrm{CO}}=E_{\text {total }}-E_{\text {surf }}-E_{\mathrm{CO}}$, where $E_{\text {total }}$ is the energy of the overall system, $E_{\text {surf }}$ is the energy of the surface without any adsorbate, and $E_{\mathrm{CO}}$ is the energy of a gas-phase $\mathrm{CO}$ molecule. A more negative adsorption energy corresponds to stronger adsorption. The $\mathrm{CO}$ vibrational modes were computed from a two-sided finite difference approximation of the dynamical matrix, with the magnitude of the displacement being $0.01 \AA$ in each degree of freedom. Zero point energies for free and adsorbed $\mathrm{CO}$ were calculated from their respective vibrational frequencies as $1 / 2 \sum h v_{i}$. Atomic charges were evaluated using the Bader method ${ }^{51}$ as implemented in the code of Henkelman and co-workers, ${ }^{52}$ which partitions the total electron density into nonoverlapping atomic volumes whose surfaces are defined as regions of zero flux in the electron density gradient.

\section{RESULTS}

3.1. CO TPD. For Au NPs deposited at $\mathrm{LN}_{2}$ (referred to hereafter as the $\mathrm{LN}_{2}$ samples, Figure 2a), and those then annealed to $600 \mathrm{~K}$ (referred to hereafter as the annealed samples, Figure 2b), CO thermal desorption started at $80 \mathrm{~K}$ with the first peak appearing at $87 \mathrm{~K}$. It is assigned to the $\mathrm{CO}$ desorption from the sample holder. The small $174 \mathrm{~K}$ peak seen for all the annealed samples (Figure $2 b$ ) and the low-coverage $(\leq 1.0 \mathrm{ML}) \mathrm{LN}_{2}$ samples (Figure $2 \mathrm{a}$ ) also appeared on the bare $h-\mathrm{BN} / \mathrm{Rh}(111)$ surface and became significantly more intense when a small amount of $\mathrm{H}_{2} \mathrm{O}$ was first deposited at $\mathrm{LN}_{2}$ before $\mathrm{CO}$ exposure (Figure S2). It is assigned to $\mathrm{CO}$ molecules trapped in amorphous ice, which were released with the desorption of the ice during the heating process. ${ }^{53}$ This assignment is supported by a single sharp $\mathrm{H}_{2} \mathrm{O}$ desorption peak at $174 \mathrm{~K}$ concomitant with $\mathrm{CO}$ desorption at $174 \mathrm{~K}$ (Figure S2). Previous STM and DFT works have shown that water at low exposures is exclusively trapped in the pores of the $h$-BN/ $\mathrm{Rh}(111)$ nanomesh, ${ }^{54}$ which is likely where ice formed in our systems, too. At high Au coverages, Au NPs occupy nearly all of the nanomesh pores on $h$-BN/Rh(111), ${ }^{28}$ which explains why the $174 \mathrm{~K}$ desorption feature appeared only on samples with less than 1.0 ML Au coverage, and why its intensity decreased with increasing Au coverage (Figure 2a). Prior STM of Au NPs supported on $h-\mathrm{BN} / \mathrm{Ru}(0001),{ }^{55}$ for which both the pore-wire structure and the morphology of deposited Au NPs are similar to $h-\mathrm{BN} / \mathrm{Rh}(111){ }^{28}$ showed that annealing to $850 \mathrm{~K}$ leads to $\mathrm{Au} \mathrm{NP}$ ripening. We postulate that annealing to $600 \mathrm{~K}$ likewise caused Au NPs to aggregate, thereby freeing up some portion of the pores that become available for ice formation (Figure 2b).

A low-temperature CO desorption peak (LTP) and a hightemperature $\mathrm{CO}$ desorption peak (HTP) from Au nanoparticles were observed for all samples in Figure 2. In general, the positional shifts of the LTPs and the HTPs as a function of the $\mathrm{Au}$ coverage, as well as the change in their relative intensities after the thermal annealing, reflect the morphology and charge state of the supported Au NPs. Both the annealed samples and the high-coverage $(\geq 1.0 \mathrm{ML}) \mathrm{LN}_{2}$ samples exhibit the LTP at $\sim 115 \mathrm{~K}$ and the HTP at $\sim 185 \mathrm{~K}$. Note that the HTP for the annealed samples largely overlaps with the $174 \mathrm{~K}$ peak in Figure $2 \mathrm{~b}$. The positions of the LTP and HTP features $(\sim 115$ and $\sim 185 \mathrm{~K})$ are reminiscent of CO desorption features from bulk $\mathrm{Au}$ crystalline surfaces. Indeed, the presence of an LTP in the range of $110-150 \mathrm{~K}$ and an HTP at $\sim 185 \mathrm{~K}$ have been characterized as a "universal phenomenon" for $\mathrm{CO}$ adsorption on bulk $\mathrm{Au}$ surfaces, with examples including $\mathrm{Au}(332),{ }^{56} \mathrm{Au}(211),{ }^{57} \mathrm{Au}(111),{ }^{58}$ and $\mathrm{Au}(110)-(1 \times 2)^{59}$ surfaces. For bulk Au crystals there is some ambiguity in the literature regarding whether these two features should be assigned to desorption from terrace and step sites $57,59,60$ or from step and kink/corner sites, respectively. ${ }^{56,58}$ However, two pieces of evidence favor the latter explanation. First, both peaks are absent for CO TPD measurements on pristine $\mathrm{Au}(111),{ }^{58}$ indicating $\mathrm{CO}$ binding to $\mathrm{Au}$ terrace sites is too weak to produce these desorption features. Second, previous DFT calculations of $\mathrm{CO}$ adsorption energies on $\mathrm{Au}$ terrace sites fall between -0.2 and $-0.3 \mathrm{eV},{ }^{61-63}$ which, when coupled with Redhead analysis assuming first-order desorption kinetics and a pre-exponential factor of $10^{13}-10^{15}$, indicates that $\mathrm{CO}$ desorption from terrace sites should occur below $\sim 115 \mathrm{~K}$. Hence, we attribute the LTP $(\sim 115 \mathrm{~K})$ and HTP $(\sim 185 \mathrm{~K})$ for both the annealed samples and the high-coverage $\mathrm{LN}_{2}$ samples to $\mathrm{CO}$ desorption from $\mathrm{Au}$ step edge and kink/corner sites, respectively.

A notable difference between the CO TPD for the highcoverage $\mathrm{LN}_{2}$ samples and the annealed samples is that the HTP dominates in the former, while the LTP dominates in the latter. In this regard, the high-coverage $\mathrm{LN}_{2}$ samples more closely resemble Au NPs grown on reactive oxide supports in terms of $\mathrm{CO}$ desorption properties. For example, Au NPs supported on $\mathrm{Al}_{2} \mathrm{O}_{3}, \mathrm{FeO}(111)$, and $\mathrm{Fe}_{3} \mathrm{O}_{4}(111)$ films all exhibit dominance of the HTP over the LTP at high Au deposition amounts, and the position of the HTP approaches $185 \mathrm{~K}$ as seen here when the Au coverage is increased. ${ }^{32,64}$ The dominance of the HTP in the high-coverage $\mathrm{LN}_{2}$ samples is likely due to a greater number of highly undercoordinated $\mathrm{Au}$ atoms compared to faceted Au NPs resulting from annealing. We postulate that the combination of the support and lowtemperature conditions prevented the Au NPs from agglomerating and faceting to become bulk-like particles even at high Au coverages. On the other hand, thermal annealing (cf. the annealed samples) evidently resulted in the faceting of the $\mathrm{Au}$ NPs and a concomitant decrease of the concentration of undercoordinated sites because the edge to kink/corner site ratios of our annealed $\mathrm{Au}$ samples match those of bulk-like $\mathrm{Au}$ crystals.

In contrast to the high-coverage $\mathrm{LN}_{2}$ samples as well as the annealed samples, the positions of the LTP and HTP for the low-coverage $\mathrm{LN}_{2}$ samples $(<1.0 \mathrm{ML}$, see Figure 2a) are coverage-dependent. Most dramatic is the shift in the HTP, which first appeared at $228 \mathrm{~K}$ for the lowest Au coverage, and gradually downshifted to $212 \mathrm{~K}$ at $1.0 \mathrm{ML}$ of Au. These values exceed those observed for crystalline Au surfaces and fall within the 210-250 K range observed for low-coverage Au NPs grown on $\mathrm{Al}_{2} \mathrm{O}_{3}, \mathrm{FeO}(111)$, and $\mathrm{Fe}_{3} \mathrm{O}_{4}(111)$ films. ${ }^{32}$ Hence, the HTP positions highlight a strong dependence of $\Delta E_{\mathrm{CO}}$ on $\mathrm{Au} N \mathrm{NP}$ size. Our previous STM and DFT analysis indicates that for $\mathrm{Au}$ coverage amounts up to $0.25 \mathrm{ML}$ on $h-\mathrm{BN} / \mathrm{Rh}(111)$ the $\mathrm{Au}$ NPs are mostly monolayer and bilayer in height. ${ }^{28}$ Such $\mathrm{Au}$ NPs possess a significant number of highly undercoordinated sites (with a coordination number ( $\mathrm{CN})$ even lower than kink/ corner sites on bulk $\mathrm{Au}$ ) than thicker Au NPs. ${ }^{63}$ Multimonolayer coverage of Au deposition results in multilayer-high $\mathrm{Au} \mathrm{NPs},{ }^{28}$ for which the number of such highly undercoordinated sites is expected to decrease significantly, causing a downshift of the CO desorption temperature. Notably, the enhanced efficacy of oxide-supported Au NPs in binding CO relative to bulk $\mathrm{Au}$ is often attributed to similar size effects and 

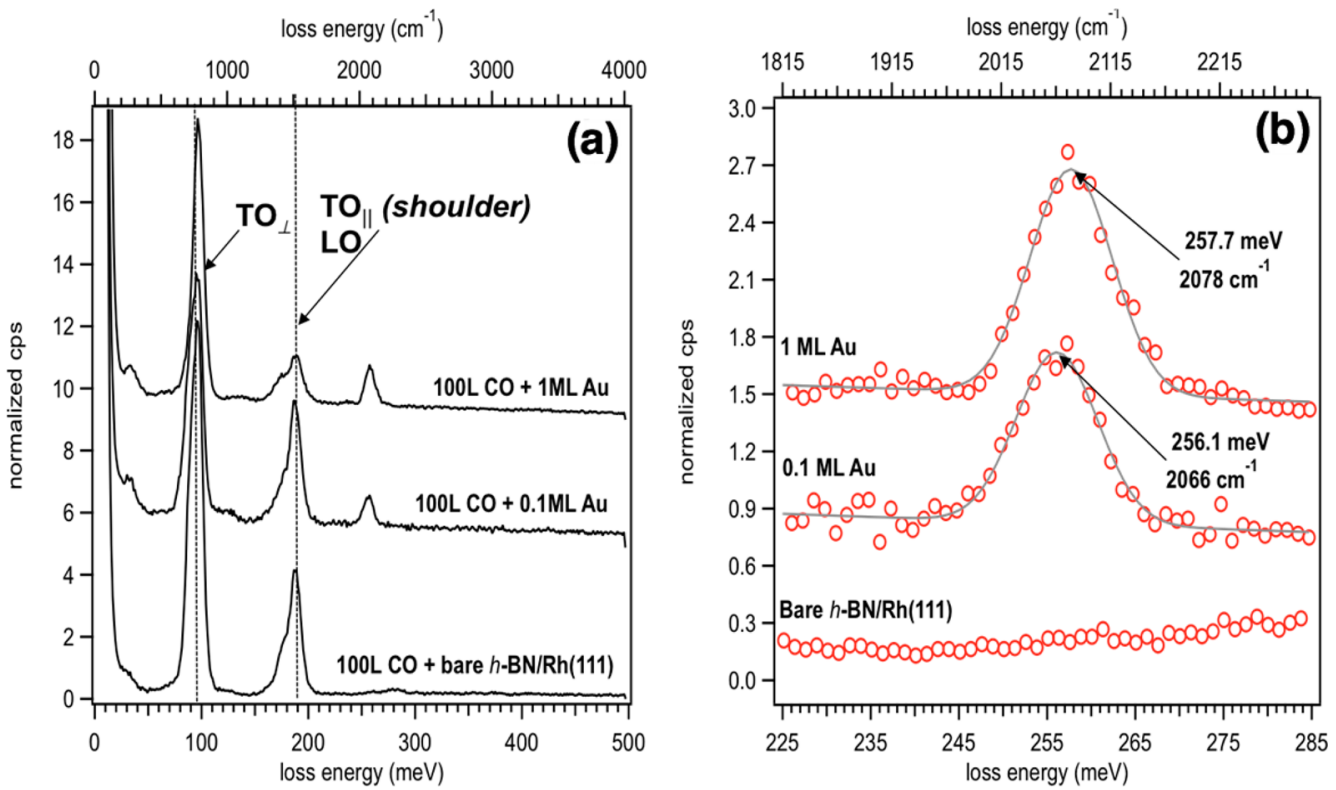

Figure 3. HREELS vibrational spectra of 100 langmuirs of $\mathrm{CO}$ dosed on bare $h$-BN/Rh(111), and on 0.1 and $1 \mathrm{ML}$ of Au deposited on $h$-BN/ $\mathrm{Rh}(111)$ at room temperature. CO dosing and measurement were done at $90 \mathrm{~K}$. (a) Survey spectra showing all recorded vibrational peaks from 0 to $500 \mathrm{meV}\left(0 \sim 4000 \mathrm{~cm}^{-1}\right)$. (b) Close-up of the $\mathrm{C}-\mathrm{O}$ stretching region. Data points are open circles, and fits to the data are solid lines. Each spectrum is fit with a single Gaussian peak using a linear background subtraction. The peak energies are indicated in bold text.

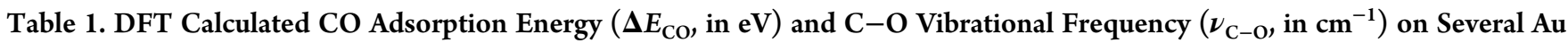
Crystal Surfaces and the $\mathrm{Au}_{30} / h-\mathrm{BN} / \mathrm{Rh}(111)$ Model Cluster

\begin{tabular}{|c|c|c|c|c|c|c|}
\hline & \multicolumn{2}{|c|}{ PBE } & \multicolumn{2}{|c|}{ BEEF } & \multirow[b]{2}{*}{$\Delta E_{\mathrm{CO}} / \mathrm{ZPE}$} & \multirow[b]{2}{*}{ peak desorption temp ${ }^{a}(\mathrm{~K})$} \\
\hline & $\Delta E_{\mathrm{CO}}$ & $\nu_{\mathrm{C}-\mathrm{O}}$ & $\Delta E_{\mathrm{CO}}$ & $\nu_{\mathrm{C}-\mathrm{O}}$ & & \\
\hline $\mathrm{Au}(111)$ & -0.39 & 2054 & -0.20 & 2050 & -0.16 & 63 \\
\hline $\mathrm{Au}(211)$ & -0.57 & 2056 & -0.32 & 2053 & -0.28 & 108 \\
\hline $\mathrm{Au}(563)$ & -0.83 & 2058 & -0.53 & 2052 & -0.49 & 186 \\
\hline $\mathrm{Au}_{30}, \mathrm{I}$ & -1.39 & 2033 & -0.69 & 2032 & -0.64 & 241 \\
\hline $\mathrm{Au}_{30}, \mathrm{II}$ & -1.42 & 2035 & -0.66 & 2029 & -0.61 & 230 \\
\hline $\mathrm{Au}_{30}, \mathrm{III}$ & -1.12 & 2047 & -0.39 & 2037 & -0.35 & 134 \\
\hline $\mathrm{Au}_{30}, \mathrm{IV}$ & -0.40 & 2100 & desorbed & & & \\
\hline
\end{tabular}

${ }^{a}$ Peak desorption temperatures were estimated using Redhead analysis assuming first-order desorption kinetics, a prefactor of $10^{13} \mathrm{~s}^{-1}$, and a temperature ramp rate of $3 \mathrm{~K} / \mathrm{s}$.

is regarded as a key component of their catalytic activity. $5,32,61$ Here, however, the highly undercoordinated sites are available on $\mathrm{Au}$ NPs in the absence of a reactive oxide support.

3.2. HREELS. The HREELS measurements were performed by dosing 100 langmuirs of $\mathrm{CO}$ at $90 \mathrm{~K}$ on a clean $h$-BN/ $\mathrm{Rh}(111)$ surface and on $h-\mathrm{BN} / \mathrm{Rh}(111)$ with 0.1 and $1.0 \mathrm{ML}$ of $\mathrm{Au}$ deposited at room temperature. The results are presented in Figure 3. On the clean $h-\mathrm{BN} / \mathrm{Rh}(111)$ surface, we identify only the transverse optical phonon peak with out-of-plane polarization $\left(\mathrm{TO}_{\perp}\right)$ at $97 \mathrm{meV}$ and the overlapping longitudinal optical (LO) and $\mathrm{TO}_{\|}$peaks at $188 \mathrm{meV}\left(782\right.$ and $1516 \mathrm{~cm}^{-1}$; the $\mathrm{TO}_{\|}$is a shoulder on the low-energy side of the LO peak), which are indicated by labeled arrows in Figure 3a. These features agree well with prior results for $h$-BN nanomeshes on $\mathrm{Rh}(111)$ and $\mathrm{Ru}(0001){ }^{65,66}$ Notably the lack of any vibrational mode that may be ascribed to $\mathrm{CO}$ precludes any significant interaction between $\mathrm{CO}$ and $h$-BN, which confirms that the $h$ $\mathrm{BN}$ nanomesh is inert to $\mathrm{CO}$ at low temperatures under $\mathrm{UHV}$ conditions. Additionally, we observed no peaks in the region of the $\mathrm{O}-\mathrm{H}$ stretching vibration $(400-450 \mathrm{meV}$ or $3200-3600$ $\mathrm{cm}^{-1}$ ) that would indicate water or hydroxyl-containing species coadsorbed during gas exposure at any temperature. Because
EELS shows no evidence of water on the surface at low temperature, we attribute the presence of water ice inferred from the TPD spectra in Figure 2 to originate from background gas in the TPD chamber that became adsorbed while cooling to $\mathrm{LN}_{2}$. The better base pressure in the EELS system $(<1.0 \times$ $10^{-10}$ Torr) leads to a substantially lower level of sample contamination.

Following deposition of $\mathrm{Au}$ at room temperature, a coveragedependent peak appeared in the $\mathrm{CO}$ stretching region signifying $\mathrm{CO}$ adsorbed onto $\mathrm{Au}$. In agreement with our TPD results, this peak disappeared for both $\mathrm{Au}$ coverages following warming to room temperature, indicating that $\mathrm{CO}$ desorption occurred. In light of the fact that our TPD measurements clearly indicate the existence of two distinct $\mathrm{CO}$ adsorption states, it is interesting to note that only one $\mathrm{CO}$ stretching feature is evident in the HREELS spectra. This characteristic is common to $\mathrm{CO}$ adsorption on both bulk $\mathrm{Au}$ crystals and supported Au NPs and indicates that the value of the CO stretching frequency is rather insensitive to $\Delta E_{\mathrm{CO}}$ and hence the $\mathrm{CN}$ of the $\mathrm{Au}$ adsorption site. Examples where $\mathrm{CO}$ adsorption onto Au leads to two distinct TPD peaks but only one $\mathrm{CO}$ stretching frequency include $\mathrm{Au}(211),{ }^{57} \mathrm{Au}(332),{ }^{56}$ 


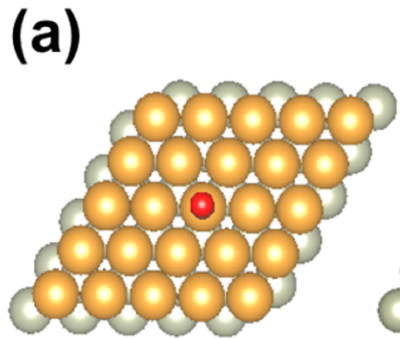

(b)

(c)

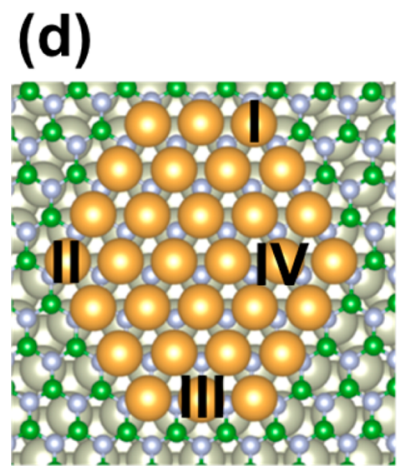

(e)

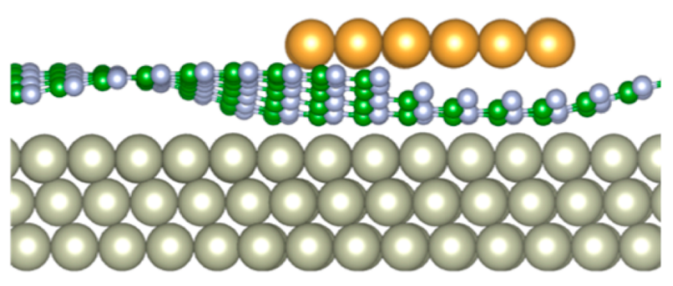

Figure 4. Models for $\mathrm{Au}$ sites of different structures: (a) $\mathrm{Au}(111)$ terrace site $(\mathrm{CN}=9)$; (b) $\mathrm{Au}(211)$ step site $(\mathrm{CN}=7)$; (c) $\mathrm{Au}(563)$ kink site $(\mathrm{CN}$ $=6)$; (d) top and (e) side views of $\mathrm{Au}_{30}$ formed in the pore region of $h-\mathrm{BN} / \mathrm{Rh}(111)$. In $(\mathrm{a}-\mathrm{c})$, the $\mathrm{CO}$ molecule indicates the sites for which $\Delta E_{\mathrm{CO}}$ is reported in Table 1; C = black; $\mathrm{O}=$ red; top layer $\mathrm{Au}=$ golden. In (d), the $\mathrm{CN}$ values for Au sites I-IV are 3, 3, 4, and 6, respectively. In (d, e), Au = golden; $\mathrm{Rh}=$ silver; $\mathrm{B}=$ green; $\mathrm{N}=$ blue.

and roughened $\mathrm{Au}(111)$ bulk crystals ${ }^{58}$ and $\mathrm{Au}$ NPs grown on $\mathrm{HPOG}^{58}$ and $\mathrm{FeO}$ thin films. ${ }^{60}$ That the $\mathrm{CO}$ stretching frequency is independent of the $\mathrm{Au} \mathrm{CN}$ (which does correlate with $\Delta E_{\mathrm{CO}}$ ) is supported by DFT calculations. Yim and coworkers have reported that $\mathrm{CO}$ binding energies on a defective $\mathrm{Au}(332)$ surface increase by $-0.10 \mathrm{eV}$ on going from an $\mathrm{Au}$ site with $\mathrm{CN}=7$ to $\mathrm{CN}=6$ and by $-0.13 \mathrm{eV}$ on going from $\mathrm{CN}=$ 6 to $\mathrm{CN}=5$. However, the calculated $\mathrm{CO}$ stretching frequency $\left(\nu_{\mathrm{C}-\mathrm{O}}\right)$ at all three sites agree within $1 \mathrm{~cm}^{-1} \cdot{ }^{58}$ Similarly, Mehmood et al. computed a $-0.14 \mathrm{eV}$ increase in $\Delta E_{\mathrm{CO}}$ on going from step to kink sites (represented by $\mathrm{Au}(211)$ vs $\mathrm{Au}(532)$, respectively), while the $\nu_{\mathrm{C}-\mathrm{O}}$ remained unchanged. ${ }^{62}$ Our DFT calculated $\nu_{\mathrm{C}-\mathrm{O}}$ (see Table 1 and section 3.3) for $\mathrm{CO}$ adsorbed on the terrace, step, and kink sites are all nearly the same, which agrees with the previous studies.

In the present study, $\nu_{\mathrm{C}-\mathrm{O}}$ appears at $2066 \mathrm{~cm}^{-1}(256.1 \mathrm{meV}$, see Figure $3 \mathrm{~b}$ ) at $0.1 \mathrm{ML}$ of Au coverage, a dramatic red-shift relative to the gas-phase $\mathrm{CO}$ molecule ${ }^{58}$ at $2143 \mathrm{~cm}^{-1}$. On charge-neutral $\mathrm{Au}$, the $\mathrm{CO}$ stretching frequency generally lies in the $2100-2120 \mathrm{~cm}^{-1}$ range ${ }^{38}$ or a red-shift of less than $45 \mathrm{~cm}^{-1}$ relative to gas-phase $\mathrm{CO}$. In contrast, the red-shift of $77 \mathrm{~cm}^{-1}$ observed here for 0.1 ML Au NPs supported on $h$-BN/ $\mathrm{Rh}(111)$, which is $32 \mathrm{~cm}^{-1}$ more red-shifted than on neutral $\mathrm{Au}$, closely resembles the $\nu_{\mathrm{C}-\mathrm{O}}$ of $\sim 2070 \mathrm{~cm}^{-1}$ for $\mathrm{CO}$ adsorbed on highly negatively charged Au NPs supported on an $\mathrm{MgO} / \mathrm{Mo}(001)$ thin film at comparable Au coverages. ${ }^{67}$ The well-known "back-donation" mechanism for explaining the redshift of the $\nu_{\mathrm{C}-\mathrm{O}}$ following $\mathrm{CO}$ adsorption on d-block metals was first proposed by Blyholder on the basis of simple Hückel MO theoretical arguments ${ }^{68}$ and posits that the TM d orbitals of the appropriate symmetry hybridize with the formerly unoccupied CO $2 \pi^{*}$ orbital to yield the partial occupancy of antibonding $\mathrm{CO}$ states, which weaken the $\mathrm{C}-\mathrm{O}$ bond (but not necessarily the $\mathrm{Au}-\mathrm{CO}$ bond). Since the degree to which such states are occupied increases with the amount of negative charge on the metal atom, Chen and Goodman have suggested that the magnitude of the red-shift of $\nu_{\mathrm{C}-\mathrm{O}}$ can serve as an experimental measure of the degree of negative charging on $\mathrm{Au}$ NPs. ${ }^{5}$ Our previous STM measurements suggest that $<0.2 \mathrm{ML}$ $\mathrm{Au}$ deposition on $h$-BN/ $\mathrm{Rh}(111)$ followed by warming to room temperature yields a mixture of mono- and bilayer $\mathrm{Au} \mathrm{NPs,}{ }^{28}$ with almost no particles exceeding two layers in height. Hence, the present red-shift is indicative of negative charging of $2 \mathrm{D} \mathrm{Au}$ NPs grown on $h-\mathrm{BN} / \mathrm{Rh}(111)$, which is also characteristic of many $\mathrm{Au}$ NP formed on TM oxides.

Increasing the $\mathrm{Au}$ coverage from 0.1 to $1.0 \mathrm{ML}$ resulted in a blue-shift of the $\nu_{\mathrm{C}-\mathrm{O}}$ from 2066 to $2078 \mathrm{~cm}^{-1}(257.7 \mathrm{meV}$, Figure $3 \mathrm{~b})$. As the coverage increase causes a transition from $\mathrm{Au}$ NPs that are one or two layers high, to clusters that are several layers high, it is reasonable to attribute the $12 \mathrm{~cm}^{-1}$ blue-shift to a decrease in the average negative charge of $\mathrm{Au}$ atoms in larger clusters. This is consistent with our previous DFT-based finding that the average negative charge density per $\mathrm{Au}$ atom strongly decreases with increasing cluster size for $\mathrm{Au}$ NPs supported on $h$-BN/Rh(111). ${ }^{28}$ Similar blue-shifts resulting from increased cluster size have also been demonstrated by Freund and co-workers for Au NPs supported on $\mathrm{FeO}^{60}$ and $\mathrm{MgO}^{67}$ thin films and were also attributed to weakened back-donation due to a decrease in the excess charge density on $\mathrm{Au}$ adsorption sites. ${ }^{67}$

3.3. DFT. We have performed DFT-based modeling of CO adsorption on several $\mathrm{Au}$ structures chosen to represent probable adsorption sites on $\mathrm{Au}$ NPs supported on $h$-BN/ $\mathrm{Rh}(111)$. We hypothesize that $\mathrm{Au}$ dosed on $h-\mathrm{BN} / \mathrm{Rh}(111)$ gains sufficient thermal energy during annealing to $600 \mathrm{~K}$ to agglomerate and restructure into NPs with bulk-like exterior surfaces. Therefore, $\mathrm{CO}$ adsorption sites on the annealed samples were represented by the $\mathrm{Au}(111),(211)$, and (563) surfaces (Figure $4 a-c)$, which correspond to close-packed terraces, step edges, and kinks, respectively. These models are 
also used to interpret the high-coverage $\mathrm{LN}_{2}$ samples, as the LTP and HTP positions in our CO TPD on 5.0 ML of Au coverage indicate a convergence of $\Delta E_{\mathrm{CO}}$ to bulk surface values and hence a transition to bulk-like properties at high $\mathrm{Au}$ coverages.

Conversely, we hypothesize that $\mathrm{Au}$ dosed at $\mathrm{LN}_{2}$ lacks the thermal energy necessary to escape the energy traps of the pore region or to even diffuse sufficiently within the pores to fully minimize the energy of individual $\mathrm{Au}$ nanoparticles. Thus, the low-coverage $\mathrm{LN}_{2}$ samples are expected to present numerous sites with an average $\mathrm{CN}$ lower than those prevalent on bulklike $\mathrm{Au}$ crystals. We model these potential low-coordination sites using a monolayer $\mathrm{Au}_{30}$ cluster located in the pore region of $h$-BN/Rh(111) (Figure 4d,e), which presents several highly undercoordinated $\mathrm{Au}$ sites for $\mathrm{CO}$ adsorption. In our previous study we have found $\mathrm{Au}_{30}$ to be approximately the size where monolayer to bilayer transition occurs for Au clusters on $h$-BN/ $\mathrm{Rh}(111) .{ }^{28}$ The general validity of $2 \mathrm{D}$ structure models for small $\mathrm{Au}$ clusters is supported by the fact that they tend to prefer flat geometries on reactive supports $32,64,67$ and that negative charging of supported $\mathrm{Au}$ clusters increases their preference for $2 \mathrm{D}$ over $3 \mathrm{D}$ structures. ${ }^{69-72}$ Furthermore, the present model is also consistent with the size and shape of $\mathrm{Au}$ NPs on $h$-BN/Rh(111) at low Au coverage and deposition temperature, as observed in our previous STM study. ${ }^{28}$

Consistent with the chemical inertness of bulk $\mathrm{Au},{ }^{73} \Delta E_{\mathrm{CO}}$ on the close-packed $\mathrm{Au}(111)$ surface is calculated to be -0.16 eV (ZPE-corrected BEEF result, same below; see Table 1). This corresponds to a peak desorption temperature of $\sim 60 \mathrm{~K}$, which is lower than the $\mathrm{CO}$ dosing temperature of $77 \mathrm{~K}$ in our TPD experiment. Thus, bulk $\mathrm{Au}(111)$ surfaces are unlikely to adsorb any $\mathrm{CO}$ in our experiments, consistent with prior studies, ${ }^{58}$ and neither the LTP in our TPD experiment nor the observed $\nu_{\mathrm{C}-\mathrm{O}}$ in HREELS can be attributed to $\mathrm{CO}$ adsorption onto terrace sites. Adsorption onto step edge sites $(\mathrm{CN}=7)$, represented here by an $\mathrm{Au}(211)$ step edge (Figure $4 \mathrm{~b}$ ), strengthens $\Delta E_{\mathrm{CO}}$ to $-0.28 \mathrm{eV}$, which is consistent with a peak desorption temperature near $110 \mathrm{~K}$. This value agrees well with the LTP feature in our TPD, supporting the assignment of this peak to $\mathrm{CO}$ desorption from step-like Au sites $(\mathrm{CN} \sim 7)$. The strongest adsorption for $\mathrm{CO}$ on a bulk $\mathrm{Au}$ surface occurs on the kink site $(\mathrm{CN}=6)^{63,74}$ on the $\mathrm{Au}(563)$ model (Figure 4c), $-0.49 \mathrm{eV}$, which corresponds to a peak desorption temperature of $\sim 185 \mathrm{~K}$, closely matching the HTP position for our highcoverage $\mathrm{LN}_{2}$ samples, as well as the HTP desorption feature observed on a variety of Au bulk crystal surfaces. Hence, our DFT results support the assignment of Yim et al. of the two CO desorption peaks on bulk-like Au particles to step and kink sites, rather than to terrace and step sites. ${ }^{58}$

While the $\mathrm{CO}$ binding energies on bulk-like $\mathrm{Au}$ particles closely correlate with the $\mathrm{CN}$ of the adsorption site, ${ }^{63}$ the calculated $\mathrm{CO}$ stretching frequencies do not. Instead, $\nu_{\mathrm{C}-\mathrm{O}}$ is essentially identical $\left(\sim 2050 \mathrm{~cm}^{-1}\right)$ on all three bulk surfaces, which lends support to the notion that the value of $\nu_{\mathrm{C}-\mathrm{O}}$ depends mainly on the charge of the Au adsorption site rather than its CN. ${ }^{5,58,67}$ Given that the experimental values of $\nu_{\mathrm{C}-\mathrm{O}}$ on charge-neutral Au fall within the range of $2100-2120 \mathrm{~cm}^{-1}$, clearly DFT produces values that are too low. This phenomenon is well documented and arises from the underestimation of the energy of the $\mathrm{CO} 2 \pi^{*}$ orbital by DFT, which yields unphysically enhanced back-donation from the metal $\mathrm{d}$ orbitals and produces $\mathrm{CO}$ stretching frequencies that are too low. ${ }^{38,75}$ Additionally, DFT is also found to underestimate the value of the gas phase $\mathrm{CO}$ stretch relative to experiment ( 2123 vs $2143 \mathrm{~cm}^{-1}$, respectively). ${ }^{58}$

Markedly different $\mathrm{CO}$ adsorption characteristics are apparent for the model $\mathrm{Au}_{30}$ cluster supported on $h$-BN/ $\mathrm{Rh}(111)$ compared to bulk Au surfaces. CO is found to desorb from the 6-fold coordinate terrace sites (site IV, Figure 4e), indicating $\mathrm{CO}$ does not adsorb on the interior of $2 \mathrm{D} \mathrm{Au}$ NPs supported on $h$-BN/Rh(111). Notably Nørskov and coworkers have reported that a freestanding monolayer of $\mathrm{Au}(111)$ terrace atoms are also unable to bind $\mathrm{CO} .{ }^{61}$ On the other hand, strong $\mathrm{CO}$ binding is found on the highly undercoordinated perimeter edge and corner sites, including 4and 3-fold coordinate $\mathrm{Au}$ atoms (sites I, II, and III in Figure $4 \mathrm{e}$ ). The calculated $\Delta E_{\mathrm{CO}}$ at the edge site (site III, Figure $4 \mathrm{e}$ ) is $-0.35 \mathrm{eV}$, which is more exothermic than a bulk step edge site (i.e., $\mathrm{Au}(211),-0.28 \mathrm{eV}$; see Table 1). The calculated $\Delta E_{\mathrm{CO}}$ at the corner sites (sites I and II, Figure $4 \mathrm{e}$ ) is $\sim-0.60 \mathrm{eV}$, which is lower than that on a bulk kink site (i.e., $\mathrm{Au}(563),-0.49 \mathrm{eV}$ ). As indicated in Table 1, the expected desorption temperature associated with $\mathrm{CO}$ bound to these corner Au sites is $\sim 230 \mathrm{~K}$, which is very near the position of the HTP for the low-coverage $\mathrm{LN}_{2}$ samples. The preferential binding of $\mathrm{CO}$ to perimeter sites has also been reported for small Au NPs supported on $\mathrm{MgO}$ films in $\mathrm{DFT}^{38}$ and $\mathrm{STM}^{67}$ studies. Perimeter-adsorbed CO molecules have been imaged directly with STM, which appear as dark depressions at the oxide film-Au NP interface.

$\mathrm{CO}$ adsorption on the edge and corner sites of the supported $\mathrm{Au}_{30}$ nanoparticle results in a red-shift of $\sim 20 \mathrm{~cm}^{-1}$ in $\nu_{\mathrm{C}-\mathrm{O}}$ relative to the values calculated for the bulk $\mathrm{Au}(111),(211)$, and (563) surfaces. This DFT calculated red-shift vs chargeneutral $\mathrm{Au}$ is in agreement with the $\sim 32 \mathrm{~cm}^{-1}$ red-shift based on our HREELS experiments mentioned above. Bader charge analysis revealed that the $\mathrm{Au}_{30}$ cluster receives a net charge of -2.23lel from the Rh support, consistent with our XPS findings. ${ }^{28}$ While an equal distribution of this excess charge over the entire particle would result in a meager average charge per $\mathrm{Au}$ atom, this is in fact not the case. Instead, $>95 \%$ of the excess charge density is calculated to localize on the perimeter atoms, with the average charges for the corner, edge, and interior sites of the $\mathrm{Au}_{30}$ being $-0.16|e|,-0.12 \mid e l$, and $-0.01 \mid e l$, respectively. The propensity for excess charge on Au NPs to localize on perimeter sites rather than to be evenly distributed throughout the cluster has previously been explained to result from the fact that the former charge distribution minimizes interelectronic repulsions. ${ }^{11}$

Negative charging of $\mathrm{Au}$ NPs on a variety of supports has been either deduced or observed by a number of authors. ${ }^{5,34}$ For example, STM imaging of Au NPs supported on an $\mathrm{MgO} /$ $\mathrm{Ag}$ surface revealed that perimeter $\mathrm{Au}$ atoms appeared as a bright rim in contrast with the darker interior atoms. ${ }^{67}$ This was attributed to the localization of additional electronic states near the Fermi level on perimeter atoms, which contain the negative charge received from the support. This interpretation is supported by differential conductance maps, where high $\mathrm{d} I$ / $\mathrm{d} V$ intensity about $E_{\mathrm{Fermi}}$ is observed only for the Au NP's perimeter atoms. ${ }^{11}$ DFT-based charge analysis suggests a -0.21 el average charge per perimeter $\mathrm{Au}$ atom on $\mathrm{MgO} / \mathrm{Ag}$ supported $\mathrm{Au} \mathrm{NPs}$, ${ }^{11}$ which is only slightly higher than that found here for the $\mathrm{Au}_{30}$ clusters supported on $h-\mathrm{BN} / \mathrm{Rh}(111)$. This is consistent with the fact that the $\mathrm{CO}$ stretching frequency for adsorbed $\mathrm{CO}$ on $\mathrm{MgO}$ film-supported $\mathrm{Au} \mathrm{NPs}$ are more red-shifted than is the present case. ${ }^{38,67}$ 
On the other hand, there is evidence that negative charging of Au actually impedes its ability to bind CO. Pacchioni and coworkers reported that $\Delta E_{\mathrm{CO}}$ on an $\mathrm{Au}$ adatom supported on $\mathrm{MgO}$ weakened by $0.6 \mathrm{eV}$ as the charge state of $\mathrm{Au}$ was changed from neutral to $-1 \mid \mathrm{el} .^{75}$ Similarly, $\Delta E_{\mathrm{CO}}$ on the corner of an $\mathrm{Au}_{12}$ cluster was found to weaken by $0.17 \mathrm{eV}$ on going from a neutral to negative charge state. ${ }^{38}$ Freund and coworkers have advanced the explanation that dative $\mathrm{CO}-\mathrm{Au}$ bonding is partially interrupted by negative $\mathrm{Au}$ charging due to impeded electron donation from the CO $5 \sigma$ orbital to the metal center. ${ }^{67}$ Taken together, these findings indicate that the very low coordination of the perimeter $\mathrm{Au}$ atoms is predominantly responsible for the enhanced adsorption of $\mathrm{CO}$, while the excess negative charge serves mainly to enhance back-donation to the $2 \pi^{*}$ orbital, thereby weakening the $\mathrm{C}-\mathrm{O}$ bond and increasing the red-shift in the $\mathrm{C}-\mathrm{O}$ vibrational frequency. The repulsive effect of the negative charging on the $\mathrm{Au}-\mathrm{CO}$ bonding, however, is outweighed by the very low coordination of the perimeter sites.

Finally, we note that the PBE CO adsorption energies are substantially larger than those given by the BEEF functional, though both functionals give nearly identical $\mathrm{CO}$ stretching frequencies. Yim et al. recently argued that the PBE functional produces $\mathrm{CO}-\mathrm{Au}$ adsorption energies that are too high to be compatible with experimental CO TPD measurements, ${ }^{38}$ which is also found to be the case here. For example, a $\Delta E_{\mathrm{CO}}$ of -0.39 $\mathrm{eV}$ on $\mathrm{Au}(111)$ (Table 1) is suggestive of a $\mathrm{CO}$ desorption peak at $\sim 150 \mathrm{~K}$, which is clearly inconsistent with the fact that $\mathrm{Au}(111)$ is unable to adsorb $\mathrm{CO}$ at low-temperature UHV conditions. Similarly, a $\Delta E_{\mathrm{CO}}$ of $-0.57 \mathrm{eV}$ on the step edge $(\mathrm{Au}(211)$, Table 1) should produce a peak desorption feature at $\sim 215 \mathrm{~K}$ in CO TPD, which is significantly higher than the $\sim 185 \mathrm{~K}$ HTP frequently observed on bulk Au crystalline surfaces. That the PW91 functional overbinds CO to metal surfaces while nonetheless producing reasonable $\mathrm{CO}$ stretching frequencies has been known. ${ }^{40}$ Specifically regarding $\mathrm{CO}-\mathrm{Au}$ bonding, Pacchioni and co-workers reported PW91 to overbind CO up to $200 \%$ relative to the highly accurate $\operatorname{CCSD}(\mathrm{T})$ wave function approach that can be expected to approach chemical accuracy (i.e., bond energies with an error bar of $\sim 0.04$ $\mathrm{eV}) .^{38,75}$ The relevance of this finding is that $\mathrm{CO}-\mathrm{Au}$ adsorption energies produced by the PBE functional are nearly the same as those given by PW91 when comparing similar adsorption sites. For instance, the $\Delta E_{\mathrm{CO}}$ on $\mathrm{Au}(111)$ and $\mathrm{Au}(211)$ computed by PW91 ${ }^{62}$ and $\mathrm{PBE}^{63}$ agree to within 0.03 $\mathrm{eV}$, while $\mathrm{CO}$ adsorption on kink sites given by PW91 ${ }^{58}$ and $\mathrm{PBE}^{63}$ agree to within $0.02 \mathrm{eV}$, despite using different surface models. Insofar as these results suggest that PBE may also overbind $\mathrm{CO}$ to $\mathrm{Au}$ significantly, the discrepancies between the $\mathrm{BEEF}$ and $\mathrm{PBE} \mathrm{CO}$ adsorption energies seen in Table 1 are therefore not unreasonable.

\section{CONCLUSIONS}

The $h$-BN/ $\mathrm{Rh}(111)$ nanomesh provides an immense array of regularly spaced trapping sites that allow deposited Au to selfassemble into dispersed Au nanoparticles (NPs). Depending on the amount of $\mathrm{Au}$ deposited, two distinct types of $\mathrm{CO}$ adsorption characteristics have been observed for Au NPs selfassembled at low temperatures.

4.1. Low Au Dosages. These NPs exhibit narrowly varied diameters and are single- to bilayer in height at the lower $\mathrm{Au}$ coverages studied. In TPD, the high-temperature CO desorption peak appears at $210-230 \mathrm{~K}$ for these $\mathrm{Au}$ NPs, whereas it occurs at $\sim 185 \mathrm{~K}$ for bulk Au crystals. DFT calculations (GGA-BEEF) for a model $2 \mathrm{D} \quad \mathrm{Au}_{30}$ cluster supported on $h$-BN/Rh(111) indicates that the highly undercoordinated perimeter edge and corner sites bind $\mathrm{CO}$ more strongly than bulk $\mathrm{Au}$ surfaces and that the $\mathrm{Au}$ cluster also contains a sizable negative charge, which is localized on the perimeter atoms. Consistent with the negative charging, $\mathrm{CO}$ stretching frequencies measured by HREELS following CO adsorption on Au NPs formed at low Au coverages (e.g., 2066 $\mathrm{cm}^{-1}$ at $0.1 \mathrm{ML}$ of $\mathrm{Au}$ ) are significantly red-shifted relative to the 2100-2120 $\mathrm{cm}^{-1}$ values observed for charge-neutral Au. Importantly, the thickness, diameter, negative charging, and $\mathrm{CO}$ adsorption characteristics of these Au NPs are all similar to catalytically active Au NPs supported on reactive metal oxides reported in the literature.

4.2. High Au Dosages. These Au NPs still exhibit tightly controlled diameters but grow in height with increasing $\mathrm{Au}$ coverage. TPD shows that both the low- and high-temperature $\mathrm{CO}$ desorption peaks occur at essentially the same temperatures as those found on bulk Au. DFT calculations indicate that for bulk-like surfaces, undercoordinated step and kink sites are most likely to bind $\mathrm{CO}$, with the adsorption energies in close agreement with the low and high peak desorption temperatures $(\sim 115$ and $\sim 185 \mathrm{~K})$. The negative charge density per $\mathrm{Au}$ atom decreases with increasing cluster size, and the HREELS measured $\mathrm{C}-\mathrm{O}$ stretching frequency blue-shifts with increasing $\mathrm{Au}$ coverage, presumably due to decreased backdonation.

4.3. Annealing to $600 \mathrm{~K}$. For both the low and high $\mathrm{Au}$ coverage samples, the high-temperature $\mathrm{CO}$ desorption peak is severely diminished after annealing to $600 \mathrm{~K}$, suggesting that elevated temperature results in $\mathrm{Au}$ diffusion and cluster agglomeration, along with faceting to diminish the concentration of highly undercoordinated $\mathrm{Au}$ sites. This yields essentially bulk-like $\mathrm{Au}$ particles.

In short, the $h$-BN/Rh(111) nanomesh provides a carbon-, oxygen-, and defect-free and inert support that allows the selfassembly of size-limited Au NPs, with morphological, charging, and $\mathrm{CO}$ adsorption characteristics similar to those associated with catalytically active Au NPs supported on reactive TM oxides. The Au NPs supported on $h$-BN/Rh(111) are therefore potential model catalysts for low-temperature $\mathrm{CO}$ oxidation and can provide valuable mechanistic insights into the role of $\mathrm{Au}$ vs support in this reaction. Furthermore, the $h$-BN/Rh(111) nanomesh may prove to be a useful model support surface capable of providing similar insights for reactions catalyzed by NPs of transition metals in the $2-3 \mathrm{~nm}$ size range in general.

\section{ASSOCIATED CONTENT}

\section{Supporting Information}

The Supporting Information is available free of charge on the ACS Publications website at DOI: 10.1021/acs.jpcc.6b01645.

An illustration of the "13-on-12" $h$-BN/ $\mathrm{Rh}(111)$ nanomesh structure used for DFT modeling and experimental $\mathrm{CO}$ and $\mathrm{H}_{2} \mathrm{O}$ TPD curves on a clean $h$-BN/Rh(111) nanomesh without $\mathrm{Au}$ (PDF)

\section{AUTHOR INFORMATION}

\section{Corresponding Authors}

*(L.L.) E-mail li.liu@tamu.edu, Tel 979-458-1090.

*(Y.X.) E-mail yexu@lsu.edu, Tel 225-578-1750. 


\section{Notes}

The authors declare no competing financial interest.

\section{ACKNOWLEDGMENTS}

This work was supported as part of the Center for Atomic Level Catalyst Design, an Energy Frontier Research Center funded by the U.S. Department of Energy, Office of Science, Office of Basic Energy Sciences (No. DE-SC0001058), and used computing resources provided by High Performance Computing, Louisiana State University and by the National Energy Research Scientific Computing Center, an Office of Science User Facility supported by the Office of Science of the U.S. Department of Energy under Contract DE-AC02$05 \mathrm{CH} 11231$.

\section{REFERENCES}

(1) Haruta, M.; Kobayashi, T.; Sano, H.; Yamada, N. Novel gold catalysts for the oxidation of carbon monoxide at a temperature far below $0^{\circ} \mathrm{C}$. Chem. Lett. 1987, 16, 405.

(2) Valden, M.; Lai, X.; Goodman, D. W. Onset of catalytic activity of gold clusters on titania with the appearance of nonmetallic properties. Science 1998, 281, 1647.

(3) Chen, M. S.; Goodman, D. W. The structure of catalytically active gold on titania. Science 2004, 306, 252.

(4) Okazaki, K.; Ichikawa, S.; Maeda, Y.; Haruta, M.; Kohyama, M. Electronic structures of Au supported on TiO. Appl. Catal., A 2005, 291, 45.

(5) Chen, M. S.; Goodman, D. W. Catalytically active gold: From nanoparticles to ultrathin films. Acc. Chem. Res. 2006, 39, 739.

(6) Herzing, A. A.; Kiely, C. J.; Carley, A. F.; Landon, P.; Hutchings, G. J. Identification of active gold nanoclusters on iron oxide supports for $\mathrm{CO}$ oxidation. Science 2008, 321, 1331.

(7) Sanchez, A.; Abbet, S.; Heiz, U.; Schneider, W. D.; Häkkinen, H.; Barnett, R. N.; Landman, U. When gold is not noble: Nanoscale gold catalysts. J. Phys. Chem. A 1999, 103, 9573.

(8) Lee, S.; Fan, C.; Wu, T.; Anderson, S. L. CO oxidation on $\mathrm{Au}_{\mathrm{n}} /$ $\mathrm{TiO}_{2}$ catalysts produced by size-selected cluster deposition. J. Am. Chem. Soc. 2004, 126, 5682.

(9) Lee, S.; Fan, C. Y.; Wu, T. P.; Anderson, S. L. Cluster size effects on $\mathrm{CO}$ oxidation activity, adsorbate affinity, and temporal behavior of model $\mathrm{Au}_{\mathrm{n}} / \mathrm{TiO}_{2}$ catalysts. J. Chem. Phys. 2005, 123, 124710.

(10) Yoon, B.; Häkkinen, H.; Landman, U.; Worz, A. S.; Antonietti, J. M.; Abbet, S.; Judai, K.; Heiz, U. Charging effects on bonding and catalyzed oxidation of $\mathrm{CO}$ on $\mathrm{Au}_{8}$ clusters on $\mathrm{MgO}$. Science 2005, 307, 403.

(11) Lin, X.; Nilius, N.; Sterrer, M.; Koskinen, P.; Häkkinen, H.; Freund, H. J. Characterizing low-coordinated atoms at the periphery of $\mathrm{MgO}$-supported $\mathrm{Au}$ islands using scanning tunneling microscopy and electronic structure calculations. Phys. Rev. B: Condens. Matter Mater. Phys. 2010, 81, 153406.

(12) Schubert, M. M.; Hackenberg, S.; van Veen, A. C.; Muhler, M.; Plzak, V.; Behm, R. J. CO oxidation over supported gold catalysts"Inert" and "active" support materials and their role for the oxygen supply during reaction. J. Catal. 2001, 197, 113.

(13) Lopez, N.; Janssens, T. V. W.; Clausen, B. S.; Xu, Y.; Mavrikakis, M.; Bligaard, T.; Nørskov, J. K. On the origin of the catalytic activity of gold nanoparticles for low-temperature CO oxidation. J. Catal. 2004, 223, 232.

(14) Liu, L. M.; McAllister, B.; Ye, H. Q.; Hu, P. Identifying an $\mathrm{O}_{2}$ supply pathway in $\mathrm{CO}$ oxidation on $\mathrm{Au} / \mathrm{TiO}_{2}(110)$ : A density functional theory study on the intrinsic role of water. J. Am. Chem. Soc. 2006, 128, 4017.

(15) Green, I. X.; Tang, W. J.; Neurock, M.; Yates, J. T. Spectroscopic observation of dual catalytic sites during oxidation of $\mathrm{CO}$ on a Au/ $\mathrm{TiO}_{2}$ Catalyst. Science 2011, 333, 736.
(16) Saavedra, J.; Doan, H. A.; Pursell, C. J.; Grabow, L. C.; Chandler, B. D. The critical role of water at the gold-titania interface in catalytic CO oxidation. Science 2014, 345, 1599.

(17) Henry, C. R. 2D-arrays of nanoparticles as model catalysts. Catal. Lett. 2015, 145, 731.

(18) N'Diaye, A. T.; Bleikamp, S.; Feibelman, P. J.; Michely, T. Twodimensional Ir cluster lattice on a graphene moire on $\operatorname{Ir}(111)$. Phys. Rev. Lett. 2006, 97, 215501.

(19) Brihuega, I.; Michaelis, C. H.; Zhang, J.; Bose, S.; Sessi, V.; Honolka, J.; Schneider, M. A.; Enders, A.; Kern, K. Electronic decoupling and templating of Co nanocluster arrays on the boron nitride nanomesh. Surf. Sci. 2008, 602, L95.

(20) Liu, L.; Zhou, Z. H.; Guo, Q. L.; Yan, Z.; Yao, Y. X.; Goodman, $\mathrm{D}$. W. The 2-D growth of gold on single-layer graphene $/ \mathrm{Ru}(0001)$ : Enhancement of CO adsorption. Surf. Sci. 2011, 605, L47.

(21) Zhou, Z. H.; Gao, F.; Goodman, D. W. Deposition of metal clusters on single-layer graphene $/ \mathrm{Ru}(0001)$ : Factors that govern cluster growth. Surf. Sci. 2010, 604, L31.

(22) Wang, B.; Bocquet, M. L. Monolayer graphene and h-BN on metal substrates as versatile templates for metallic nanoclusters. J. Phys. Chem. Lett. 2011, 2, 2341.

(23) Soy, E.; Liang, Z.; Trenary, M. Formation of Pt and Rh nanoclusters on a graphene moire pattern on $\mathrm{Cu}(111)$. J. Phys. Chem. C 2015, 119, 24796.

(24) Bunk, O.; Corso, M.; Martoccia, D.; Herger, R.; Willmott, P. R.; Patterson, B. D.; Osterwalder, J.; van der Veen, J. F.; Greber, T. Surface X-ray diffraction study of boron-nitride nanomesh in air. Surf. Sci. 2007, 601, L7.

(25) Berner, S.; Corso, M.; Widmer, R.; Groening, O.; Laskowski, R.; Blaha, P.; Schwarz, K.; Goriachko, A.; Over, H.; Gsell, S.; et al. Boron nitride nanomesh: Functionality from a corrugated monolayer. Angew. Chem., Int. Ed. 2007, 46, 5115.

(26) Gerber, T.; Knudsen, J.; Feibelman, P. J.; Granas, E.; Stratmann, P.; Schulte, K.; Andersen, J. N.; Michely, T. CO-induced Smoluchowski ripening of $\mathrm{Pt}$ cluster arrays on the graphene/ $\operatorname{Ir}(111)$ moire. ACS Nano 2013, 7, 2020.

(27) Gotterbarm, K.; Späth, F.; Bauer, U.; Bronnbauer, C.; Steinrück, H.-P.; Papp, C. Reactivity of graphene-supported Pt nanocluster arrays. ACS Catal. 2015, 5, 2397.

(28) Patterson, M. C.; Habenicht, B. F.; Kurtz, R. L.; Liu, L.; Xu, Y.; Sprunger, P. T. Formation and stability of dense arrays of $\mathrm{Au}$ nanoclusters on hexagonal boron nitride/ $\mathrm{Rh}(111)$. Phys. Rev. B: Condens. Matter Mater. Phys. 2014, 89, 205423.

(29) Corso, M.; Auwarter, W.; Muntwiler, M.; Tamai, A.; Greber, T.; Osterwalder, J. Boron nitride nanomesh. Science 2004, 303, 217.

(30) Laskowski, R.; Blaha, P.; Gallauner, T.; Schwarz, K. Single-layer model of the hexagonal boron nitride nanomesh on the $\mathrm{Rh}(111)$ surface. Phys. Rev. Lett. 2007, 98, 106802.

(31) Laskowski, R.; Blaha, P. Unraveling the structure of the h-BN/ $\mathrm{Rh}(111)$ nanomesh with ab initio calculations. J. Phys.: Condens. Matter 2008, 20, 064207.

(32) Shaikhutdinov, S. K.; Meyer, R.; Naschitzki, M.; Bäumer, M.; Freund, H. J. Size and support effects for $\mathrm{CO}$ adsorption on gold model catalysts. Catal. Lett. 2003, 86, 211.

(33) Koch, H. P.; Laskowski, R.; Blaha, P.; Schwarz, K. Adsorption of gold atoms on the h-BN/Rh(111) nanomesh. Phys. Rev. B: Condens. Matter Mater. Phys. 2011, 84, 245410.

(34) Xu, Y.; Semidey-Flecha, L.; Liu, L.; Zhou, Z.; Goodman, D. W. Exploring the structure and chemical activity of 2-D gold islands on graphene moire $/ \mathrm{Ru}(0001)$. Faraday Discuss. 2011, 152, 267.

(35) Habenicht, B. F.; Teng, D.; Semidey-Flecha, L.; Sholl, D. S.; Xu, Y. Adsorption and diffusion of $4 \mathrm{~d}$ and $5 \mathrm{~d}$ transition metal adatoms on graphene $/ \mathrm{Ru}(0001)$ and the implications for cluster nucleation. Top. Catal. 2014, 57, 69.

(36) Teng, D.; Sholl, D. S. Adsorption and diffusion of Rh and Au dimers and trimers on graphene $/ \mathrm{Ru}(0001)$. Surf. Sci. 2014, 626, 6.

(37) Ng, M. L.; Preobrajenski, A. B.; Vinogradov, A. S.; Martensson, $\mathrm{N}$. Formation and temperature evolution of $\mathrm{Au}$ nanoparticles supported on the h-BN nanomesh. Surf. Sci. 2008, 602, 1250. 
(38) Sicolo, S.; Giordano, L.; Pacchioni, G. CO adsorption on one-, two-, and three-dimensional Au clusters supported on $\mathrm{MgO} / \mathrm{Ag}(001)$ ultrathin films. J. Phys. Chem. C 2009, 113, 10256.

(39) Stiehler, C.; Calaza, F.; Schneider, W.-D.; Nilius, N.; Freund, H.$\mathrm{J}$. Molecular adsorption changes the quantum structure of oxidesupported gold nanoparticles: Chemisorption versus physisorption. Phys. Rev. Lett. 2015, 115, 036804.

(40) Gajdos, M.; Eichler, A.; Hafner, J. CO adsorption on closepacked transition and noble metal surfaces: trends from ab initio calculations. J. Phys.: Condens. Matter 2004, 16, 1141.

(41) Thiel, P. A.; Williams, E. D.; Yates, J. T., Jr.; Weinberg, W. H. The chemisorption of CO on Rh(111). Surf. Sci. 1979, 84, 54.

(42) Winkler, A.; Yates, J. T. Capillary array dosing and angular desorption distribution measurements: A general formalism. J. Vac. Sci. Technol., A 1988, 6, 2929.

(43) Kresse, G.; Furthmüller, J. Efficiency of ab-initio total energy calculations for metals and semiconductors using a plane-wave basis set. Comput. Mater. Sci. 1996, 6, 15.

(44) Perdew, J. J.; Burke, K.; Ernzerhof, M. Generalized gradient approximation made simple. Phys. Rev. Lett. 1996, 77, 3865.

(45) Wellendorff, J.; Lundgaard, K. T.; Møgelhøj, A.; Petzold, V.; Landis, D. D.; Nørskov, J. K.; Bligaard, T.; Jacobsen, K. W. Density functionals for surface science: Exchange-correlation model development with Bayesian error estimation. Phys. Rev. B: Condens. Matter Mater. Phys. 2012, 85, 235149.

(46) Kresse, G.; Joubert, D. From ultrasoft pseudopotentials to the projector augmented-wave method. Phys. Rev. B: Condens. Matter Mater. Phys. 1999, 59, 1758.

(47) Methfessel, M.; Paxton, A. T. High-precision sampling for Brillouin-zone integration in metals. Phys. Rev. B: Condens. Matter Mater. Phys. 1989, 40, 3616.

(48) Ashcroft, N. W.; Mermin, N. D. Solid State Physics; Saunders College: Orlando, FL, 1976.

(49) Neugebauer, J.; Scheffler, M. Adsorbate-substrate and adsorbateadsorbate interactions of $\mathrm{Na}$ and $\mathrm{K}$ adlayers on $\mathrm{Al}(111)$. Phys. Rev. B: Condens. Matter Mater. Phys. 1992, 46, 16067.

(50) McKee, W. C.; Meunier, V.; Xu, Y. Reconciling the electronic and geometric corrugations of the hexagonal boron nitride and graphene nanomeshes. Surf. Sci. 2015, 642, L16.

(51) Bader, R. F. W. Atoms in Molecules - A Quantum Theory; Oxford University Press: Oxford, 1990.

(52) Tang, W.; Sanville, E.; Henkelman, G. A grid-based Bader analysis algorithm without lattice bias. J. Phys.: Condens. Matter 2009, 21, 084204 .

(53) Collings, M. P.; Dever, J. W.; Fraser, H. J.; McCoustra, M. R. S.; Williams, D. A. Carbon monoxide entrapment in interstellar ice analogs. Astrophys. J. 2003, 583, 1058.

(54) Ma, H.; Brugger, T.; Berner, S.; Ding, Y.; Iannuzzi, M.; Hutter, J.; Osterwalder, J.; Greber, T. Nano-ice on boron nitride nanomesh: Accessing proton disorder. ChemPhysChem 2010, 11, 399.

(55) Goriachko, A.; He, Y. B.; Over, H. Complex growth of nanoAu on $\mathrm{BN}$ nanomeshes supported by $\mathrm{Ru}(0001)$. J. Phys. Chem. C 2008, $112,8147$.

(56) Ruggiero, C.; Hollins, P. Adsorption of carbon monoxide on the gold(332) surface. J. Chem. Soc., Faraday Trans. 1996, 92, 4829.

(57) Kim, J.; Samano, E.; Koel, B. E. CO adsorption and reaction on clean and oxygen-covered $\mathrm{Au}(211)$ surfaces. J. Phys. Chem. B 2006, $110,17512$.

(58) Yim, W. L.; Nowitzki, T.; Necke, M.; Schnars, H.; Nickut, P.; Biener, J.; Biener, M. M.; Zielasek, V.; Al-Shamery, K.; Kluner, T.; et al. Universal phenomena of $\mathrm{CO}$ adsorption on gold surfaces with lowcoordinated sites. J. Phys. Chem. C 2007, 111, 445.

(59) Gottfried, J. M.; Schmidt, K. J.; Schroeder, S. L. M.; Christmann, $\mathrm{K}$. Adsorption of carbon monoxide on $\mathrm{Au}(110)-(1 \times 2)$. Surf. Sci. 2003, 536, 206.

(60) Lemire, C.; Meyer, R.; Shaikhutdinov, S.; Freund, H. J. Do quantum size effects control $\mathrm{CO}$ adsorption on gold nanoparticles? Angew. Chem., Int. Ed. 2004, 43, 118.
(61) Mavrikakis, M.; Stoltze, P.; Nørskov, J. K. Making gold less noble. Catal. Lett. 2000, 64, 101.

(62) Mehmood, F.; Kara, A.; Rahman, T. S.; Henry, C. R. Comparative study of $\mathrm{CO}$ adsorption on flat, stepped, and kinked $\mathrm{Au}$ surfaces using density functional theory. Phys. Rev. B: Condens. Matter Mater. Phys. 2009, 79, 075422.

(63) Zeng, Z. H.; Greeley, J. Theoretical study of CO adsorption on $\mathrm{Au}$ catalysts under environmental catalytic conditions. Catal. Commun. 2014, 52, 78

(64) Lemire, C.; Meyer, R.; Shaikhutdinov, S. K.; Freund, H. J. CO adsorption on oxide supported gold: from small clusters to monolayer islands and three-dimensional nanoparticles. Surf. Sci. 2004, 552, 27.

(65) Farkas, A. P.; Török, P.; Solymosi, F.; Kiss, J.; Kónya, Z. Investigation of the adsorption properties of borazine and characterisation of boron nitride on $\mathrm{Rh}(111)$ by electron spectroscopic methods. Appl. Surf. Sci. 2015, 354 (Part B), 367.

(66) Nai, C. T.; Lu, J.; Zhang, K.; Loh, K. P. Studying edge defects of hexagonal boron nitride using high-resolution electron energy loss spectroscopy. J. Phys. Chem. Lett. 2015, 6, 4189.

(67) Lin, X.; Yang, B.; Benia, H. M.; Myrach, P.; Yulikov, M.; Aumer, A.; Brown, M. A.; Sterrer, M.; Bondarchuk, O.; Kieseritzky, E.; et al. Charge-mediated adsorption behavior of $\mathrm{CO}$ on $\mathrm{MgO}$-supported $\mathrm{Au}$ clusters. J. Am. Chem. Soc. 2010, 132, 7745.

(68) Blyholder, G. Molecular orbital view of chemisorbed carbon monoxide. J. Phys. Chem. 1964, 68, 2772.

(69) Ricci, D.; Bongiorno, A.; Pacchioni, G.; Landman, U. Bonding trends and dimensionality crossover of gold nanoclusters on metalsupported $\mathrm{MgO}$ thin films. Phys. Rev. Lett. 2006, 97, 036106.

(70) Landman, U.; Yoon, B.; Zhang, C.; Heiz, U.; Arenz, M. Factors in gold nanocatalysis: Oxidation of $\mathrm{CO}$ in the non-scalable size regime. Top. Catal. 2007, 44, 145.

(71) Frondelius, P.; Häkkinen, H.; Honkala, K. Adsorption of gold clusters on metal-supported MgO: Correlation to electron affinity of gold. Phys. Rev. B: Condens. Matter Mater. Phys. 2007, 76, 073406.

(72) Sterrer, M.; Risse, T.; Heyde, M.; Rust, H.-P.; Freund, H.-J. Crossover from three-dimensional to two-dimensional geometries of $\mathrm{Au}$ nanostructures on thin $\mathrm{MgO}(001)$ films: A confirmation of theoretical predictions. Phys. Rev. Lett. 2007, 98, 206103.

(73) Hammer, B.; Nørskov, J. K. Why gold is the noblest of all the metals. Nature 1995, 376, 238.

(74) Piccolo, L.; Loffreda, D.; Aires, F.; Deranlot, C.; Jugnet, Y.; Sautet, P.; Bertolini, J. C. The adsorption of $\mathrm{CO}$ on $\mathrm{Au}(111)$ at elevated pressures studied by STM, RAIRS and DFT calculations. Surf. Sci. 2004, 566, 995.

(75) Giordano, L.; Carrasco, J.; Di Valentin, C.; Illas, F.; Pacchioni, G. Vibrational and electron paramagnetic resonance properties of free and $\mathrm{MgO}$ supported AuCO complexes. J. Chem. Phys. 2006, 124, 174709 . 